\title{
MUJER JOVEN CON TUMORACIÓN EN AURÍCULA DERECHA
}

\section{YOUNG WOMAN WITH A TUMOR IN THE RIGHT ATRIUM}

\section{Aline TROVO ${ }^{1}$, Lourdes VÁZQUEZ ${ }^{1}$, Michelle BRÍTEZ ${ }^{1}$, Silvia GABRIAGUEZ ${ }^{1}$, Edgar LÓPEZ1, Idalina STANLEY ${ }^{1}$ \\ ${ }^{1}$ Universidad Nacional de Asunción, Facultad de Ciencias Médicas, Departamento de Nefrología, San Lorenzo, Paraguay.}

Cómo citar este artículo: Trovo A, Vázquez L, Brítez M, Gabriaguez S, López E, Stanley I. Mujer joven con tumoración en aurícula derecha. Med. clín. soc. 2019;3(1):34-38.

\section{RESUMEN}

El presente caso clínico trata de una paciente de 28 años, en hemodiálisis por Nefritis Lúpica en quien se encuentra una masa intracardiaca en aurícula derecha, hallazgo casual en ecocardiografía transtorácica (ETT) pre trasplante renal, con alta sospecha de trombo por ecocardiografía transesofágica (ETE). Se realiza exéresis del tumor y se confirma por anatomía patológica trombo organizado.

Palabras clave: Masa cardíaca; trombo; lupus; enfermedad renal crónica.

\section{ABSTRACT}

This case report concerns a 28-year-old patient on hemodialysis due to Lupus Nephritis in whom there is an intracardiac mass in the right atrium, a casual finding in transthoracic echocardiography (TTE) before kidney transplantation, with high suspicion of thrombus by transesophageal echocardiography (TEE). The tumor is excised and confirmed a thrombus by pathological anatomy.

Keywords: Heart mass; thrombus; lupus; chronic kidney disease.

\section{INTRODUCCIÓN}

Las tumoraciones cardíacas son poco frecuentes, y pueden ser de tipo neoplásicas y no neoplásicas (1). Estas últimas están representadas por los trombos, que constituyen las más frecuentes (1-3). Los trombos ubicados en las cavidades cardíacas derechas provienen con mayor frecuencia de la circulación venosa periférica, pero, aunque en menor proporción, también pueden ser originados in situ (4). Están asociados a enfermedades autoinmunes (5-6).

\section{PRESENTACIÓN DEL CASO CLÍNICO}

Paciente femenino de 28 años de edad con diagnóstico de Nefritis Lúpica e hipertensión arterial desde febrero de 2017, con mala evolución al tratamiento inmunosupresor por lo que tuvo que iniciar hemodiálisis (HD) a través de catéter yugular temporal desde abril del 2017. 
Tres meses después inicia estudios pre trasplante, en ecocardiografía transtorácica (ETT) se observa como hallazgo casual en la aurícula derecha una imagen hipodensa, poco móvil, 39 $\mathrm{mm}$ por $30 \mathrm{~mm}$ que impresiona adherida al catéter de hemodiálisis, compatible con probable trombo, no observada en ETT realizado al inicio de la terapia sustitutiva renal. En la ecocardiografía transesofágica (ETE) se observa una imagen redondeada, homogénea, poco móvil adherida a pared auricular de $30 \times 20 \mathrm{~mm}$ que no impresiona estar adherida al catéter de hemodiálisis. Al examen físico se encontraba normotensa, afebril y con frecuencia cardiaca conservada, sin signos de insuficiencia cardíaca.

En reunión clínico quirúrgica se decide la exéresis del tumor localizado en la aurícula derecha. La misma se realiza en julio del 2017. En la anatomía patológica (Fig. 2-3) se describe un coágulo fibrinohemático adosado a tejido conectivo con focos de microcalcificaciones, no observándose presencia de colonias bacterianas, siendo una vegetación trombótica no bacteriana, sin proceso neoplásico asociado. En ETT post cirugía cardíaca ya no se observa la vegetación, con fracción de eyección del 61\%, septum levemente hipoquinético y paradojal post operatorio, derrame pericardio leve a moderado e hipertensión pulmonar leve.

Los potenciales auditivos del tronco encefálico (PATE), evidencian hipoacusia sensorioneural severa en oído izquierdo y normalidad a la derecha. Se sospecha en fistula LCR hacia oído medio como punto de partida de la meningitis. Es sometido a dos cirugías por técnica conservadora sin éxito. En un tercer intento se decide obliterar el vestíbulo. Se prepara al paciente con catéter peridural en el espacio subaracnoideo para disminuir la presión del LCR a nivel de la fístula. Se procede a la timpanotomía exploradora y cierre de fístula: como hallazgo intraoperatorio se constata una fistula con débito importante por delante de la ventana oval. Se remueve el yunque para mejora exposición.

Se remueve el estribo exponiendo la ventana oval con salida abundante de LCR. Se procede al llenado del vestíbulo con músculo, consiguiendo controlar la salida de LCR, se cierra la ventana oval con cartílago con pericondrio y sobre el mismo, músculo más pegamento biológico. Se llena la caja timpánica y mastoidea con trozos de músculo y se reposiciona el colgajo meatotimpánico. Se mantiene el drenaje lumbar por 3 días y se lo medica con azetazolamida y cefazolina. Recibió el alta a los 10 días del posoperatorio. Hasta la fecha no ha presentado meningitis. Su último control audiológico evidencia pérdida sensorioneural moderada del lado contralateral y actualmente es usuario de audífono convencional de ese lado y con buen aprovechamiento.

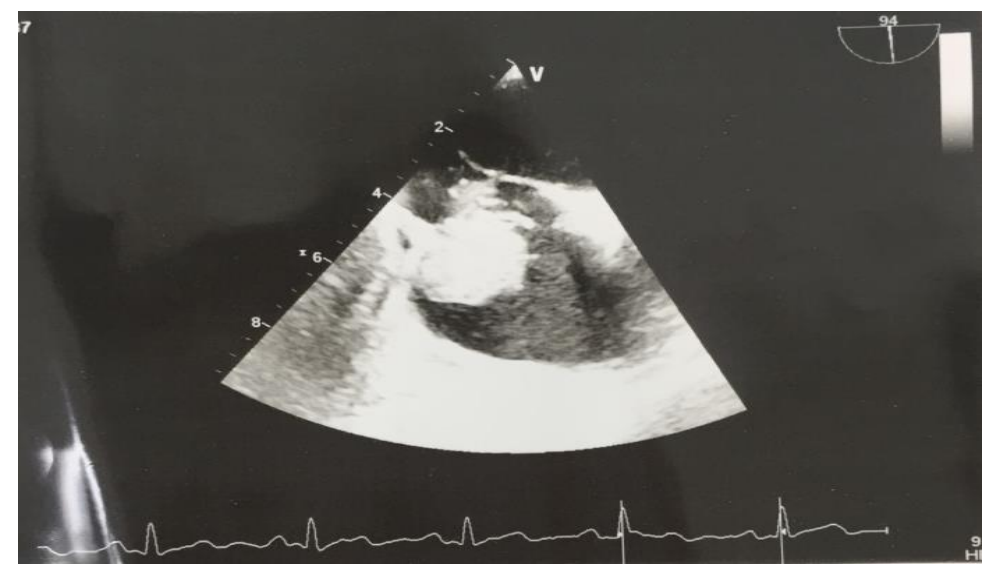

Fig. 1. Ecocardiografía transesofágica. Se evidencia imagen redondeada, inhomogénea, poco móvil, adherida a pared auricular: $30 \mathrm{~mm}$ por $20 \mathrm{~mm}$. No adherida a catéter de hemodiálisis. 


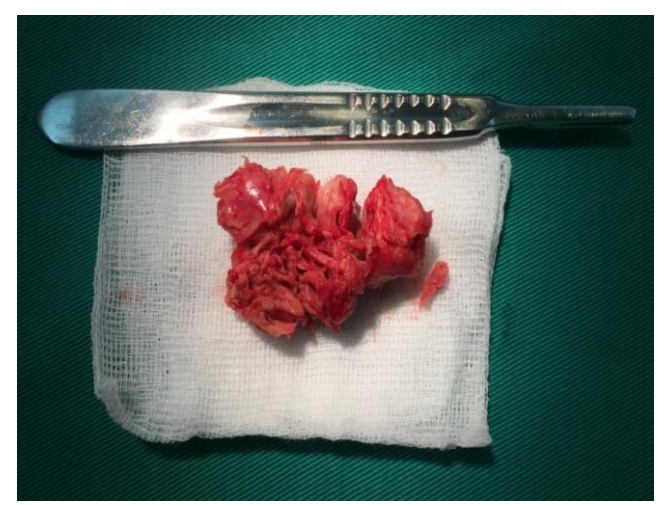

Figura 2. Macroscopía: Fragmento irregular que mide $45 \times 30 \times 20 \mathrm{~mm}$, amarronado, heterogéneo, con fibrina, al corte se observa tejido heterogéneo, de consistencia sólida blanda con áreas firmes.

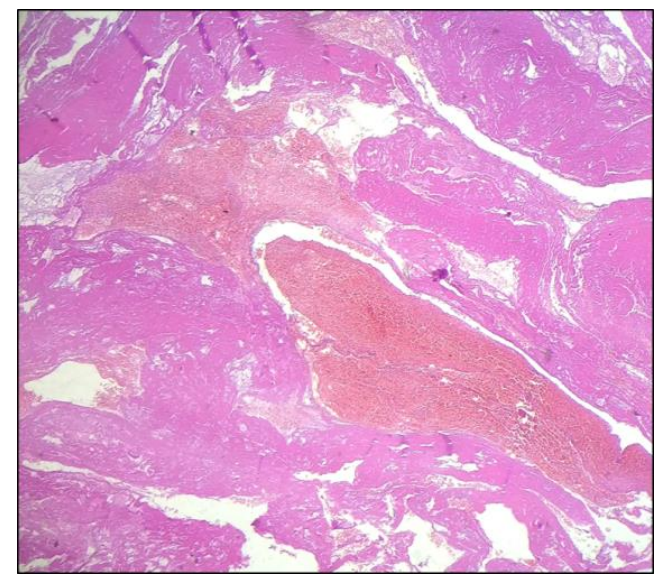

Figura 3. Microscopía: Coágulo fibrinohemático adosado a tejido conectivo con focos de microcalcificaciones. Trombo organizado con calcificaciones. No se observa proceso neoplásico.

\section{DISCUSIÓN}

Los tumores cardíacos se clasifican en primarios y secundarios. Los tumores cardíacos primarios son muy poco frecuentes, entre ellos se encuentran las neoplasias benignas y malignas que pueden desarrollarse a partir de cualquier tejido cardíaco. Los tumores cardíacos secundarios o metastásicos son 30 veces más frecuentes que los primarios (2).

Entre los tumores cardíacos primarios que afectan las aurículas uno de los más frecuentes son los mixomas, el $80 \%$ se originan en la aurícula izquierda, siendo con menor frecuencia en la aurícula derecha (7). Adoptan típicamente una forma de masa pedunculada de base corta y ancha, pero también pueden presentar forma sésil. $Y$ además tienden a estar relacionados a fenómenos embólicos. Uno de los diagnósticos diferenciales a tener en cuenta en este tipo de pacientes con tumores o masas cardíacas son los trombos intracavitarios (5).

La aparición de trombos intracavitarios, especialmente los hallados en la aurícula derecha son una complicación poco frecuente de los catéteres de hemodiálisis, y suelen ser hallazgos casuales debido a que los pacientes generalmente no presentan síntomas (1).

Los trombos ocurren en el contexto de estasis sanguínea, pueden ser laminares o esféricos de bordes bien delimitados con amplia base de implantación y densidad ecocardiográfica mayor que la del miocardio. Uno de los mecanismos involucrados con el uso de catéteres de hemodiálisis parece ser el trauma mecánico repetido a la pared auricular (5). 
Los trombos se clasifican en dos grupos, tipos A son coágulos de alta movilidad, probablemente originados a partir de una trombosis venosa profunda, y tipo B coágulos inmóviles. Los de tipo A se asocian a alta mortalidad debido a tromboembolismo pulmonar (TEP). Y los de tipo $B$ con un curso más benigno, en donde el tratamiento con antagonistas de la vitamina $\mathrm{K}$ suele ser suficiente (8). En el caso de nuestra paciente debido a las características halladas en la ETT y la ETE, y al no haber signos de trombosis venosa profunda, pertenecía al grupo $B$, de acuerdo con esta clasificación.

La ecocardiografía transtorácica es el método de elección para su detección y seguimiento. La ecocardiografía transesofágica permite una mejor visualización de estas con una sensibilidad cercana al $100 \%$ para el diagnóstico de trombos frente a la ETT con una sensibilidad del $68 \%(9)$.

En pacientes con trombos de gran tamaño la trombectomía quirúrgica es el tratamiento de elección, en los casos que no son candidatos a cirugía por riesgo prohibitivo se debe considerar el tratamiento con anticoagulación o trombólisis. Y la anticoagulación de por vida en casos de estados hipercoagulables, especialmente en pacientes en hemodiálisis crónica a través de un catéter (1).

\section{CONFLICTOS DE INTERÉS Y FUENTE DE FINANCIACIÓN}

Los autores declaran no poseer conflictos de interés. Fuente de financiación: ninguna.

\section{REFERENCIAS BIBLIOGRÁFICAS}

1. Stavroulopoulos A, Aresti V, Zounis C. Right atrial thrombi complicating haemodialysis catheters. A meta-analysis of reported cases and a proposal of a management algorithm. Nephrol Dial Transplant. 2012;27(7):2936-2944. https://doi.org/10.1093/ndt/gfr739

2. Mason JC. Tumores que afectan al sistema cardiovascular. En: Mann DL, Douglas P. Zipes, Libby $P$, et al, editores. Braunwald Tratado de Cardiología. Vol 2. 10ma ed. España: Elsevier; 2016. p. 1863-1875.

3. Pérez D, García M, García M, Zamorano J, Ferreirós J, Lafuente J, et al. Utilidad de la resonancia magnética en el estudio de las masas cardiacas y de la afección pericárdica. Rev Esp Cardiol. 2006; 6:30-40. https://doi.org/10.1157/13092057

4. Al-Halaseh $\mathrm{W}$, Shah N, De Gregorio J. Right ventricular thrombus mimicking a myxoma in a 19 year old man. Hosp Physician. 2005; 41:39-42. URL.

5. Benjamin MM, Afzal A, Chamogeorgakis T, Feghali GA. Right atrial thrombus and its causes, complications, and therapy. Proc (Bayl Univ Med Cent). 2017;30:54-56. URL.

6. Guitton Z, Terriou L, Lega JC, Nove-Josserand R, Hie M, Amoura Z, Bussel JB, et al. Risk of thrombosis with anti-phospholipid syndrome in systemic lupus erythematosus treated with thrombopoietin-receptor agonists. Rheumatology (Oxford). 2018;1;57(8):1432-1438. https://doi.org/10.1093/rheumatology/key119 
7. Muñoz D, García E, Páez J, Hernández E. Mixoma gigante de aurícula derecha. Presentación de un caso. Cir Cardiov. 2013;20(4):203-205. https://doi.org/10.1016/i.circv.2013.06.006

8. Valenzuela LF, Gallego P, Rodríguez M, Calvo R, Pavón R, Moreno R, et al. Trombo en tránsito en aurícula derecha: diagnóstico ecocardiográfico 72 horas antes de un embolismo pulmonar. Rev Esp Cardiol. 1999;52(1):59-62. URL.

9. Aravena F, Araya N, Morales J, Carabantes J, Sanhueza P. Masa cardíaca derecha, a propósito de un caso. Rev Chil Cardiol. 2013;32(1):66-70. http://dx.doi.org/10.4067/\$0718-85602013000100010 